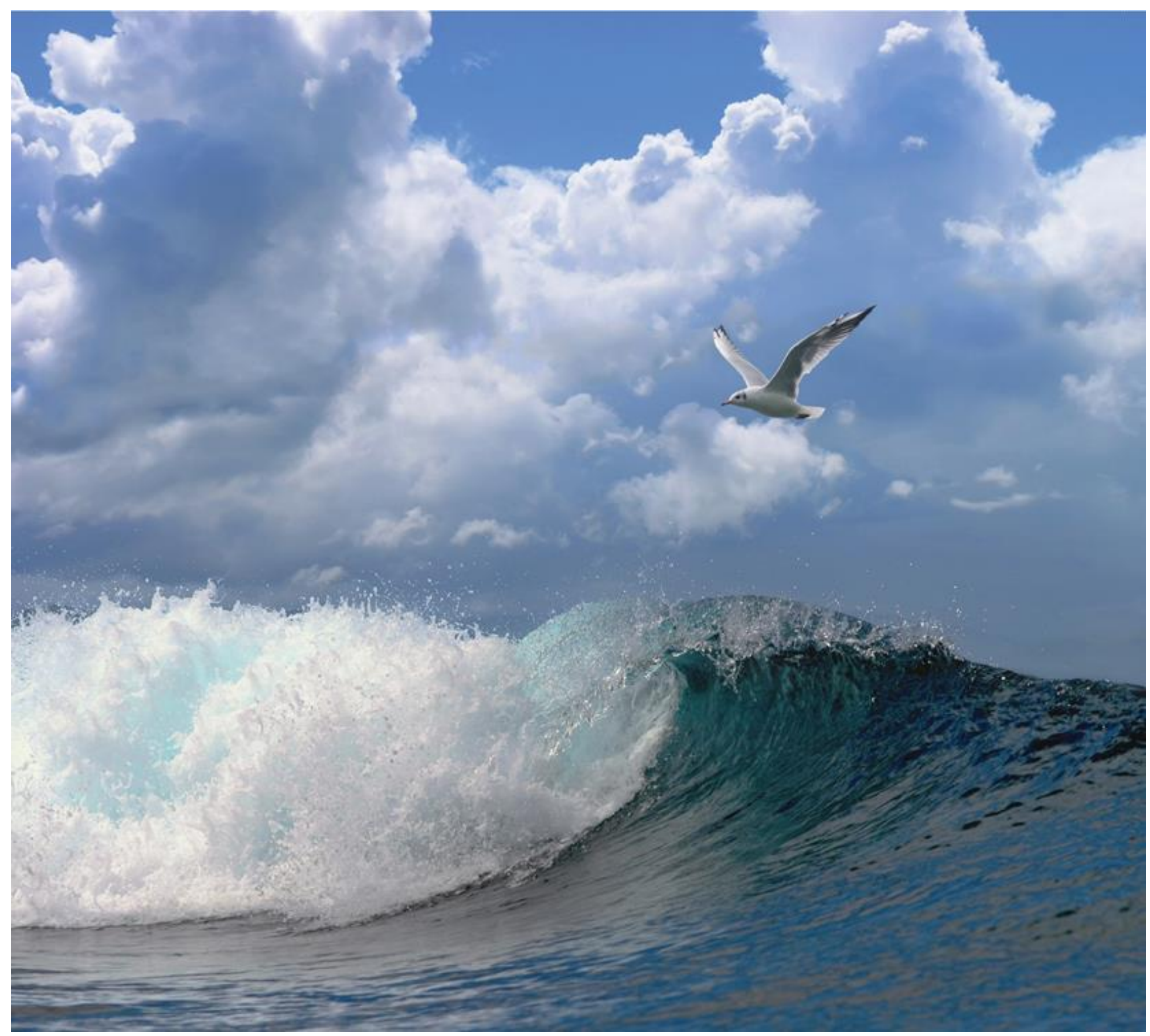

Common Guillemots and offshore wind farms: an ecological discussion of statistical analyses conducted by Alain F. Zuur WOZEP Birds-1 


\section{Common Guillemots and offshore wind farms: an ecological discussion of statistical analyses conducted by Alain F. Zuur}

(WOZEP Birds-1)

Author: $\quad$ Dr. Mardik F. Leopold

Publication date: $6^{\text {th }}$ December 2018 
Leopold M.F., 2018. Common Guillemots and offshore wind farms: an ecological discussion of statistical analyses conducted by Alain Zuur (WOZEP Birds-1). Wageningen, Wageningen Marine Research (University \& Research centre), Wageningen Marine Research report C093/18.

Keywords: Offshore wind farm, guillemot, Uria aalge displacement,

Client: Dir. Veiligheid en Watergebruik. Afd. Waterkwaliteit en Natuurbeheer Rijkswaterstaat Water Verkeer en Leefomgeving

T.a.v.:, Ingeborg van Splunder

Zuiderwagenplein 2

8224 AD Lelystad

This report can be downloaded for free from https://doi.org/10.18174/466106

Wageningen Marine Research provides no printed copies of reports

Wageningen Marine Research is ISO 9001:2008 certified.

(C) 2016 Wageningen Marine Research Wageningen UR

Wageningen Marine Research The Management of Wageningen Marine Research is not responsible for resulting institute of Stichting Wageningen damage, as well as for damage resulting from the application of results or Research is registered in the Dutch research obtained by Wageningen Marine Research, its clients or any claims traderecord nr. 09098104, related to the application of information found within its research. This report BTW nr. NL 806511618 has been made on the request of the client and is wholly the client's property. This report may not be reproduced and/or published partially or in its entirety without the express written consent of the client. 


\section{Contents}

1 Introduction $\quad 4$

2 Assignment $\quad 5$

$3 \quad$ The available data $\quad 6$

3.1 Wind farms and data sets 6

3.2 Earlier analyses of these data $\quad 6$

$4 \quad$ Statistical methods used by Alain Zuur in $2018 \quad 7$

$\begin{array}{llr}5 & \text { Results } & 8\end{array}$

$\begin{array}{llr}6 & \text { Recommendations } & 10\end{array}$

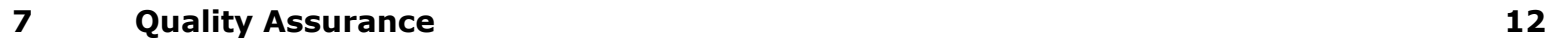

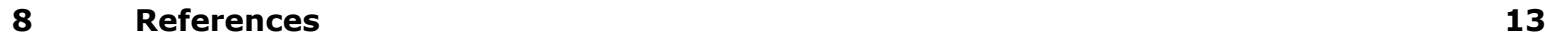

$\begin{array}{lr}\text { Justification } & 15\end{array}$ 


\section{Introduction}

Offshore wind farms in the North Sea and elsewhere are rapidly becoming more numerous. Jointly, offshore wind farms may cover $>10 \%$ of the surface area of the southern North Sea within two decades. Although wind power will clearly contribute to lessening global $\mathrm{CO}_{2}$ emissions, building up the seas may also have negative environmental consequences. One of these may be, that seabirds will be displaced from a rapidly increasing amount of surface area, thereby losing more and more of their atsea habitat (Leopold et al. 2014). Whether or not this will have consequences for their vital rates or population development is currently unknown. However, such negative effects of the development of offshore wind farms can only occur, if seabirds are displaced, or if they would e.g., stop foraging within offshore wind farms. Should displacement impact the vital rates of the birds concerned, for instance because the available space at sea is limiting survival or population size, the latter will be pushed towards a new population size that is in equilibrium with the remaining habitat availability, at some level below the initial starting population (Busch et al. 2015).

Seabird presence in and around offshore wind farms has been studied in many sites and the general conclusion of these studies is, that effects vary with species. Some species appear to show little or no reaction to the presence of offshore wind farms, but others have been reported to be displaced. At least one species, the great cormorant, is clearly attracted by offshore wind farms (reviews in Furness et al. 2013; Krijgsveld 2014; Dierschke et al. 2016).

Two avenues might be open to mitigate displacement effects on seabirds. The first would be to avoid building offshore wind farms in prime seabird habitats. Nearshore waters, directly in front of colonies would need to be avoided (if only to avoid direct mortality through collisions; Stienen et al. 2008), as would be areas that are particularly rich in vulnerable seabirds (Leopold \& Dijkman 2010). The second mitigation measure could be the design of offshore wind farms. Birds might respond differently to different turbine sizes, turbine densities or turbine configurations within a wind farm. To the human observer, a wind farm with larger turbines, placed further apart from each other, "looks different" from a wind farm with smaller, but more densely packed turbines.

Given that "search areas" for further offshore wind energy development have already largely be designated, the second approach (benign wind farm design) might be an important way forward. However, before ecologists or marine spatial planners should attempt to steer wind farm engineers towards such "benign" designs, three fundamental questions should be answered. First, it should be clear that seabirds avoid entering offshore wind farms, and/or that they change their behaviour when inside. Second, the consequences of displacement on vital rates should be assessed and third, the effects of different wind farm designs should be studied.

Displacement has been studied in the same species, the common guillemot (Uria aalge) in wind farms across the North Sea and adjoining waters. Some studies have reported displacement in this species (e.g., Leopold et al. 2013; Vanermen et al. 2014; Skov et al. 2016) but others reported little or no displacement in guillemots (Vallejo et al. 2017). As guillemots are numerous and widely occurring in most parts of the North Sea (Skov et al. 2007), this species might be the ideal study bird to examine displacement in different offshore wind farms. Moreover, the strength of displacement in this species appears to vary, be it with location, season or wind farm (design). A variable response is needed to test effect strength. In other words, a species that either is displaced completely from all wind farms, or, alternatively, that shows no reaction to any wind farm, or that only occurs in very few wind farms, would not be suitable for a comparative study. 


\section{Assignment}

Two studies preceded the current analysis. An international workshop was held in Den Helder in April 2017, bringing together seabird researchers and guillemot displacement data for offshore wind farms in Denmark, Germany, The Netherlands, Belgium and the UK. All studies shared a common general design, that used seabird (all species, not just guillemots) counts along pre-designed transect lines through an offshore wind farm. Both ship-based and aerial survey data were brought to the workshop and the various data sets were analysed using a common approach, that was being developed during the workshop (led by Dr Alain Zuur, of Highland Statistics). Given that data sets still needed screening and that the latest statistical methods for analysing such data were to be used, and that the data structure was very difficult to work with (see below), a common end result could not be reached at the workshop. Therefore, Dr Alain Zuur re-analysed the available data sets again, one by one, after the workshop and reported on the results of his analysis in a technical report (Zuur 2018). The report written by Zuur (2018) focuses on the analysis of the available data. This report attempts to provide advice on how best to proceed with further field studies, and to explain, in more layman's terms, how good or imperfect the available data were and how the statistical challenge of working with these data was approached. 


\section{The available data}

\subsection{Wind farms and data sets}

Data available at and after the workshop of April 2017 consisted of seabirds at sea survey data for the offshore wind farms: OWEZ (Offshore Windfarm Egmond aan Zee) and PAWP (Prinses Amalia Windpark) off the mainland coast of The Netherlands, Robin Rigg in the Solway Firth, SW Scotland; Alpha Ventus in the German Bight of the North Sea (Germany), Blighbank and Thorntonbank (Belgium), Horns Rev (Denmark) and Sheringham Shoal (off the coast of Norfolk, England). Most data come from offshore wind farms in the North Sea, with the exception of those for Robin Rigg (UK west coast).

\subsection{Earlier analyses of these data}

Displacement of guillemots has been reported from earlier analyses for OWEZ and PAWP (Leopold et al. 2013); Blighbank and Thorntonbank (Vanermen et al. 2014), Alpha Ventus (Mendel et al. 2014); Horns Rev (Petersen et al. 2006). However, an absence of guillemot displacement was recently reported for Robin Rigg (Vallejo et al. 2017). This last wind farm has guillemots in all months of the year, while the others only have guillemots in the non-breeding seasons. 


\section{$4 \quad$ Statistical methods used by Alain Zuur in 2018}

All available data sets were first evaluated (cf. Zuur et al. 2010) and were found to have certain serious common problems that needed attention before these could be analyzed. First, the data contained very large numbers of zero counts: parts of the data with effort (a certain surface area of sea observed) but with no guillemots seen. This problem, of many zeros within large data sets, has only recently been incorporated into spatio-statistical modelling of seabirds (Zuur et al. 2014). The general solution to this problem is to use so-called zero-inflated Poisson (ZIP) models. The second problem is, that count results within the data sets are not independent. Both high and low counts tend to cluster, both in time and in space. This is a serious violation of the independence assumption, underlying traditional statistical analysis techniques. Spatial autocorrelation therefore needs to be incorporated in the analyses, in this case a Poisson generalized linear model (GLM; cf. Zuur et al. 2013). The temporal effect, i.e., the fact that one survey could predict, to some extent, the results of the next, was initially covered by adding 'survey' (as a random effect), but in the INLA approach more advanced spatial dependency structures were incorporated in the model. Finally, not all counts are equally long and wide, resulting in variation in surface areas observed between individual counts. Clearly, if a large area is being observed, the probability that a guillemot is present is also larger, all other things being equal. To accommodate for this, 'Area' was used in the models as a co-variate.

Before the (final) analyses were conducted, it was tested which additions to the models were needed to improve the results. Several models were tested, from basic to more complex, and the results were compared by examining the values of WAIC (Widely Available Information Criterion; Watanabe 2010) or of DIC (Deviance Information Criterion), the Bayesian version of the perhaps better known AIC (Akaike Information Criterion; Akaike 1973) often used in in frequentist analysis; the lower the WAIC (or DIC) the better the model. In the results presented by Zuur (2018) the best model was always identified by both WAIC and DIC.

Given that the data sets typically contained many zeros, spatial correlation, temporal correlation and non-linear patterns (see below), the statistical analysis was a major challenge and required advanced statistical methods. The method of choice was R-INLA, which is a relatively new method in seabird spatial analysis, capable of incorporating the issues mentioned above. See further Zuur et al. (2017) for a more extensive, but still nontechnical explanation. 


\section{$5 \quad$ Results}

The first issue that needed to be addressed was the large number of zeros (counts with no guillemots) in the data sets. An initial analysis of the OWEZ and PAWP area showed that the distribution patterns showed large between-surveys variation, meaning that is was necessary to analyse the data at survey level. At this level, several individual surveys were meaningless, as they contained only zeros:

guillemots are non-breeding visitors to these wind farms and were completely absent in some summer surveys, while some other surveys had only very few non-zero observations (see Appendix A-C in Zuur (2018)). After considering this problem, it was decided to omit all surveys with more than $75 \%$ of zeros from the analyses. In effect, this meant that all results from the Blighbank and Thorntonbank, Alpha Ventus, Horns Rev, and Sheringham Shoal offshore wind farms were not further analysed. Even though earlier analyses (on aggregated data) had suggested that these data either showed or did not show guillemot displacement from the respective offshore wind farms, Zuur (2018) considered these data unsuitable for a more advanced analysis with the developed R-INLA method. Therefore, only the data sets of OWEZ and PAWP (The Netherlands) and of Robin Rigg (SW Scotland) remained.

With the R-INLA technique, a grid of triangular cells is laid over the area with survey data. Cell size increased from the inside out and there are more cells (a finer grid) than survey data points. For each node in the grid, guillemot density is modelled (a probability value is generated) and these can be plotted as a so-called spatial random field: a two-dimensional image of guillemot densities. These results were plotted as heat maps, with red areas showing above average densities and blue areas below average densities. These were then compared to the footprint of the wind farm, or, rather, the relative numbers of high and low densities (at the nodes) were compared for different distances to the offshore wind farm (centre of gravity). The analyses yielded several, rather surprising results:

First, the heat maps (the spatial random fields) proved to be highly variable over time: these changed dramatically from survey to survey. This means, that guillemot density varied greatly in time and space: high density areas in one survey could be low density areas in another. And second, this variation seemed to be rather independent from wind farm presence. In other words, waves of contracting and expanding concentrations of guillemots pulsed through the wind farm areas, dwarfing any displacement effects the wind farms might have. Although some displacement seemed apparent in individual surveys, displacement was inconsistent in the OWEZ and PAWP data (contra: Leopold et al. 2013; Zuur et al. 2014), while a very weak displacement was found for Robin Rigg (contra Vallejo et al. 2017 who reported "no displacement", and note that Zuur is one of the authors of the 2014 study). However, the 2014 analyses were carried out using generalized additive mixed effects models (GAMM). The spatial correlation was modelled with random effects, which is not as good as INLA. Note that, when the analyses were carried out in 2013 R-INLA was in the process of being developed. The fact that the outcome of the current analysis is at odds with earlier, less advanced analyses, would seem to suggest that the statistical method of choice determines the outcome. However, in the opinion of Alain Zuur (pers. comm.) the previous sentence is not correct. INLA is a major statistical improvement as compared to the GLMMs that were applied in 2010-2013. New statistical methods will appear in the future, obviously, but whatever will be developed, another big step for spatial GLMs such as INLA is unlikely to become available soon. And whatever will be developed, it seems highly unlikely that anything can cope with $99 \%$ zeros and only a few positive sampling locations around a wind farm.

There were clear spatial patterns in the distribution patterns of the birds in and around wind farms at sea. However, these spatial patterns differ per survey and there is no consistent pattern in these spatial distributions. This means, that analyses of combined surveys (for the same wind farm) may be misleading. The data from the Alpha Ventus, Blighbank en Thorntonbank, Horns Rev and Sheringham Shoal Offshore wind farms do not allow for the analysis of individual surveys due to the large number of zeros for guillemots. 
The fact that the distribution patterns of guillemots were found to be so variable, needs further consideration. At sea, everything is constantly in motion, excepting the location of an offshore wind farm. We do not know, as we have not been able to follow individual birds continuously, how guillemots move through the study areas. It seems reasonable to suggest that the birds move in response to (or are driven by) their physical environment. The tides are constantly pulling birds in one direction or the next, while they may also be displaced by wind and waves. On top of this come responses to biological parameters, such as the presence of food. Unlike seaduck, that eat sedentary (fixed in place) shellfish, guillemots eat fish and fish move, probably responding to the same physical parameters as the birds, but in different ways. As we only know what guillemots eat in general terms, from stomach contents analyses of beached birds or birds returning to breeding colonies (i.e. birds found displaced from the location where they ate their last meal), we have no clue how guillemots respond, at sea, to passing fish schools. In addition, guillemots have a broad winter diet, that includes a large range of sizes, species, and both pelagic and demersal fish species (Ouwehand et al. 2004), so linking guillemot movements to one particular prey species would probably be unjustified. We know that some fish species tend to concentrate around offshore wind farm monopiles (Lindeboom et al. 2011, Degraer et al. 2016), but implying, from this, that offshore wind farms might thus be attractive to guillemots is wishful thinking, until we know that these birds forage in offshore wind farms, what fish they eat, and how these fish relate to the wind farm.

What we do know, or can infer from this study and others, is that guillemots are highly mobile seabirds, that move over the seas in response to many different stimuli, of which an offshore wind farm may be one amongst many. The results of the analyses offered by Zuur (2018) of guillemot survey data in and around several offshore wind farms show that each survey is different, at least for the three wind farms with the best-quality data. With the exception of Robin Rigg, where there is a small similarity over time, these wind farms are not the most important agents that steer guillemot movements at sea. 


\section{Recommendations}

Zuur reports that analysing survey data, like available for this study, requires a lot of computing power. Some data sets were even so large / complex in combination with the gridding requirements of R-INLA that they were too large be handled as intended (paragraph A.2.2 Technical information, in Zuur 2018). Initial data exploration also showed, that it is rather pointless to go out and survey in an off-season, when guillemots reside elsewhere and when mostly zero counts are collected. On the other hand, a given wind farm is unlikely to affect just one species of interest and the presence of several species of interest is unlikely to overlap entirely in time. In the future, multi-species analyses might also become a possibility.

Note that the data analysed by Zuur (2018) concerned only one species, the common guillemot. The reason for this was, that guillemots occur in large numbers over large areas, and were supposedly present in good numbers in all offshore wind farms included in the study. Moreover, some, to considerable displacement in this species had been reported earlier, in response to offshore wind farms. The fact that the latest analyses (Zuur 2018) found no, or very little displacement, only refers to this species and not to all seabirds that might be affected by offshore wind farms. A recent study on displacement in divers (Gavia sp.) by Mendel et al. (2019) showed "profound changes in distribution patterns of these birds (mainly red-throated divers (Gavia stellata)". Other seabirds, such as northern gannets (Morus bassanus), may also be easier displaced by offshore wind farms than the common guillemot (Dierschke et al. 2016).

Considering the common guillemot: another important lesson learnt is that guillemot distribution in any one study site is highly variable in time, but given that the best temporal survey resolution was once per month (Robin Rigg) we have still no idea how fast distribution patterns at sea might change. Therefore, we also do not know how "representative" survey results are: if patterns are very different in two successive months, how different would these be in successive weeks, days, hours or tidal cycles? Given that some displacement could only be demonstrated for Robin Rigg, the offshore wind farm that was surveyed most times, and with a relatively high frequency (once per month, over several years), it would seem advisable to enhance survey frequencies in future studies.

Future surveys of offshore wind farm areas should probably also better consider the species of interest. Past survey routines tended to cover all species, in all seasons, resulting in many "zeros" for each species. It would probably be better to first consider which species are truly the species of interest in a given situation (wind farm) and concentrate all effort on that species. Surveys that are often repeated are probably more valuable than surveys that are conducted at large temporal intervals.

How birds move across the sea in general should be known first, before any inferences can be made about how they would respond to one particular stimulus, given that they probably respond to multiple stimuli at any one time. We should thus invest in continuous observations, either by using GPS trackers, or from fixed vantage points (Leopold \& Verdaat 2018). GPS trackers are probably most promising, but studying guillemots in their winter quarters would seem problematic. Several hundreds of birds have been, or will soon be, equipped with GPS trackers in colonies along the UK east coasts (Dr Bob Furness, pers. comm.), but even with hundreds of devices deployed, there is no guarantee that tracked birds will move towards (Dutch) offshore wind farms (in numbers sufficiently large for a robust analyses of the effects of Dutch offshore wind farms). However, offshore wind farms may impact seabirds in a similar way in all seasons and all places (as also indicated by the year-round results of the Robin Rigg study). Therefore, it might be possible to tag birds in colonies close to offshore wind farms, e.g. in the UK or at Helgoland, Germany. Birds tagged here have a relatively high probability of visiting wind farms areas and results from the vicinity of breeding colonies can probably be used to infer displacement in other situations, in the non-breeding season, as well. The problem 
could alternatively be approached from the other side, by catching guillemots in or close to the offshore wind farms where they winter. It is now possible to catch such birds at sea and put trackers on them (Dr Ramunas Zydelis, pers. comm.), so it should be possible to equip wintering birds with trackers. If these would stay, for some time at least, in the area where they were caught, their tracked movements could shed light on their immediate responses to offshore wind farms in the area. 


\section{Quality Assurance}

Wageningen Marine Research utilises an ISO 9001:2008 certified quality management system (certificate number: 187378-2015-AQ-NLD-RvA). This certificate is valid until 15 September 2018. The organisation has been certified since 27 February 2001. The certification was issued by DNV Certification B.V. 


\section{$8 \quad$ References}

Akaike H. 1973. Information theory and an extension of the maximum likelihood principle. In: B.N. Petrov \& F. Csaki (eds). Proceedings of the Second International Symposium on Information Theory, Budapest: Akademiai Kiado, pp 267-281. Reprinted in S. Kotz (ed.) 1992. Breakthroughs in Statistics. New York: Springer pp 610-624.

Busch M., Buisson R., Barrett Z., Davies S. \& Rehfisch, M. 2015. Developing a habitat loss method for assessing displacement impacts from offshore wind farms. JNCC Report 551, Peterborough.

Degraer, S., Brabant R., Rumes B., Vigin L. (Eds.) 2016. Environmental impacts of offshore wind farms in the Belgian part of the North Sea: Environmental impact monitoring reloaded. Royal Belgian Institute of Natural Sciences, OD Natural Environment, Marine Ecology and Management Section.

Dierschke V., Furness R.W. \& Garthe S. 2016. Seabirds and offshore wind farms in European waters: Avoidance and attraction. Biological Conservation 202: 59-68

Furness R.W., Wade H.M. \& Masden E.A. 2013. Assessing vulnerability of marine bird populations to offshore wind farms. Journal of Environmental Management 119: 56-66.

Krijgsveld K.L. 2014. Avoidance behaviour of birds around offshore wind farms. Overview of knowledge including effects of configuration. Rapport Bureau Waardenburg 13-268.

Leopold M.F. \& Dijkman E.M. 2010. A North Sea map of seabird vulnerability for offshore wind farms. In: van der Wal et al. 2010. Windspeed Report D3.3; IMARES Report C058/10, pp 32-40.

Leopold M. \& Verdaat H. 2018. Reacties zeevogels in windparken bij doorvaart. Wageningen University \& Research rapport C024/18; http://library.wur.nl/WebQuery/wurpubs/fulltext/446354.

Leopold M.F., van Bemmelen R.S.A. \& Zuur A.F. 2013. Responses of local birds to the offshore wind farms PAWP and OWEZ off the Dutch mainland coast. IMARES Report C151/12; http://edepot.wur.nl/279573.

Leopold M.F., Booman M., Collier M.P., Davaasuren N., Fijn R.C., Gyimesi A., de Jong J., Jongbloed R.H., Jonge Poerink B., Kleyheeg-Hartman J., Krijgsveld K.L., Lagerveld S., Lensink R., Poot M.J.M. van der Wal J.T. \& Scholl M. 2014. A first approach to deal with cumulative effects on birds and bats of offshore wind farms and other human activities in the Southern North Sea. IMARES Report C166/14; http://library.wur.nl/WebQuery/wurpubs/482985.

Lindeboom H.J., Kouwenhoven H.J., Bergman M.J.N., Bouma S., Brasseur S., Daan R., Fijn R.C., de Haan D., Dirksen S., van Hal R., Hille Ris Lambers R., ter Hofstede R., Krijgsveld K.L., Leopold M. \& Scheidat M. 2011. Short-term ecological effects of an offshore wind farm in the Dutch coastal zone; a compilation. Environ. Res. Lett. 6 (2011) 035101.

Mendel B., Kotzerka J., Sommerfeld J., Schwemmer H., Sonntag N. \& Garthe S. 2014. Effects of the alpha ventus offshore test site on distribution patterns, behaviour and flight heights of seabirds. in: Federal Maritime and Hydrography Agency, Federal Ministry for the Environment \& Nature Conservation and Nuclear Safety (Eds) 2014. Ecological Research at the Offshore Windfarm alpha ventus, DOI 10.1007/978-3-658-02462-8_11. Springer Fachmedien Wiesbaden, pp 95-110.

Mendel B., Schwemmer P., Peschko V., Müller S., Schwemmer H., Mercker M. \& Garthe S. 2019. Operational offshore wind farms and associated ship traffic cause profound changes in distribution patterns of loons (Gavia spp.). Journal of Environmental Management 231: 429438.

Ouwehand J., Leopold M.F. \& Camphuysen C.J. 2004. A comparative study of the diet of guillemots Uria aalge and razorbills Alca torda killed during the Tricolor oil incident in the south-eastern North Sea in January 2003. Atlantic Seabirds (special issue) 6: 147-166.

Petersen I.K., Christensen T.K., Kahlert J., Desholm M. \& Fox A.D. 2006. Final results of bird studies at the offshore wind farms at Nysted and Horns Rev, Denmark. NERI Report, commissioned by DONG energy and Vattenfall A/S, 161p.

Skov H., Durinck J., Leopold M.F. \& Tasker M.L. 2007. A quantitative method for evaluating the importance of marine areas for conservation of birds. Biological Conservation 136: 362-371. 
Skov H., Heinänen S., Lazcny M. \& Chudzinska M. 2016. Offshore Windfarm Eneco Luchterduinen. Ecological monitoring of seabirds, T1 report. Confidential Report, Project number 11813060, IfAÖ \& DHI for ENECO.

Stienen E.W.M., Courtens W.,Everaert J \& Van de walle M. 2008. Sex-biased mortality of common terns in wind farm collisions. Condor 110: 154-157.

Vallejo G.C., Grellier K., Nelson E.J., McGregor R.M., Canning S.J., Caryl F.M. \& McLean N. 2017. Responses of two marine top predators to an offshore wind farm. Ecology and Evolution. 2017: 1-11.

Vanermen N., Onkelinx T., Courtens W., Van de walle M., Verstraete H. \& Stienen E.W.M. 2014. Seabird avoidance and attraction at an offshore wind farm in the Belgian part of the North Sea. Hydrobiologia: DOI 10.1007/s10750-014-2088-x.

Watanabe S. 2010. Asymptotic equivalence of Bayes cross validation and Widely Applicable Information Criterion in singular learning theory. Journal of Machine Learning Research 11: 3571-3594.

Zuur A.F., Ieno E.N. \& Elphick C.S. 2010. A protocol for data exploration to avoid common statistical problems. Methods in Ecology and Evolution 1: 3-14.

Zuur A.F., Hilbe J.M. \& Ieno E.N. 2013. Beginner's Guide to GLM and GLMM with R. Newburgh, UK: Highland Statistics.

Zuur A.F., van Bemmelen R.S.A. \& Leopold M.F. 2014. Zero-inflated sea bird data sampled at offshore wind farms. Ch 6 (pp 145-186) in: A.F. Zuur, A.A. Saveliev \& E.N. Ieno. A Beginner s Guide to Generalised Additive Mixed Models with R. Published by Highland Statistics Ltd., Newburgh, United Kingdom.

Zuur A.F., Ieno E.N., \& Saveliev A.A. 2017. Beginner's Guide to Spatial, Temporal and SpatialTemporal Ecological Data Analysis with RINLA. Newburgh, UK: Highland Statistics.

Zuur A.F. 2018. Effects of wind farms on the spatial distribution of guillemots. Unpublished report. 


\section{Justification}

Report C093/18

Project Number: 4315100068

The scientific quality of this report has been peer reviewed by a colleague scientist and a member of the Management Team of Wageningen Marine Research

Approved: $\quad$ Dr A.F. Zuur

Signature:

Date:

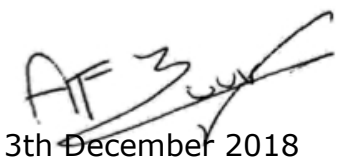

Approved: $\quad$ Drs Jakob Asjes

Manager integration/Wageningen Marine Research

Signature:

Date:

6th December 2018 
Wageningen Marine Research

$\mathrm{T}+31(0) 317480900$

E: marine-research@wur.nl

www.wur.eu/marine-research

Visitors' address

- Ankerpark 27, 1781 AG Den Helder

- Korringaweg 7, 4401 NT Yerseke

- Haringkade 1, 1976 CP IJmuiden
Wageningen Marine Research is the Netherlands research institute established to provide the scientific support that is essential for developing policies and innovation in respect of the marine environment, fishery activities, aquaculture and the maritime sector.

\section{Wageningen University \& Research:}

is specialised in the domain of healthy food and living environment.

\section{The Wageningen Marine Research vision}

'To explore the potential of marine nature to improve the quality of life'

\section{The Wageningen Marine Research mission}

- To conduct research with the aim of acquiring knowledge and offering advice on the sustainable management and use of marine and coastal areas.

- Wageningen Marine Research is an independent, leading scientific research institute

Wageningen Marine Research is part of the international knowledge organisation Wageningen UR (University \& Research centre). Within Wageningen UR, nine specialised research institutes of the Stichting Wageningen Research Foundation have joined forces with Wageningen University to help answer the most important questions in the domain of healthy food and living environment. 